\title{
Efficacy of high dose vitamin D supplementation in improving serum 25-hydroxyvitamin D among laboratory personnel working at the Nepal National Center for Rheumatic Diseases
}

\author{
MOHAN GIRI, BIBHUTI UPRETI, RAKSHYA JOSHI, \\ JAYANTI CHAMLING RAI and BINIT VAIDYA \\ National Center for Rheumatic Diseases, Ratopul, Kathmandu 44600, Nepal \\ Received September 15, 2017; Accepted September 21, 2017
}

DOI: $10.3892 /$ br.2017.1000

\begin{abstract}
Vitamin D deficiency is a highly prevalent condition worldwide. However, few studies have been conducted to examine the vitamin D status of laboratory personnel and the correlation between vitamin D deficiency and working conditions. The aim of the present study was to assess changes in serum 25-hydroxyvitamin D [25(OH)D] concentration with a weekly dose of oral cholecalciferol $(60,000 \mathrm{IU})$ for two months. The prospective, open-label, interventional study was conducted from January 2016 to March 2016 at the National Centre for Rheumatic Diseases, Kathmandu, Nepal. The serum level of $25(\mathrm{OH}) \mathrm{D}$ in 19 healthy laboratory volunteers was measured at baseline and following the 2-month regimen with cholecalciferol supplement at 60,000 IU $(1,500 \mu \mathrm{g}) /$ week in oral tablet form. At baseline the mean serum 25(OH)D level was $10.31 \pm 7.78 \mathrm{ng} / \mathrm{ml}$, which was increased following completion of the course of oral cholecalciferol to $59.78 \pm 14.74 \mathrm{ng} / \mathrm{ml}$. This difference in the mean serum level of $25(\mathrm{OH}) \mathrm{D}$ compared with baseline was significant to $\mathrm{P}<0.001$. These results indicate that vitamin $\mathrm{D}$ deficiency is prevalent among laboratory workers, and that high dose vitamin D3 (60,000 IU cholecalciferol) in tablet form may be effective in achieving sufficient serum $25(\mathrm{OH}) \mathrm{D}$ among laboratory personnel who tend to have lower baseline serum $25(\mathrm{OH}) \mathrm{D}$. In conclusion, vitamin $\mathrm{D}$ deficiency may be common among laboratory workers, and guidelines should be formulated to implement vitamin D supplementation among laboratory personnel, as well as indoor workers, in Nepal.
\end{abstract}

Correspondence to: Dr Binit Vaidya, National Center for Rheumatic Diseases, 4 Pashupati Road, Ratopul, Kathmandu 44600, Nepal

E-mail: drbinitvaidya@yahoo.com

Key words: vitamin D deficiency, serum 25-hydroxyvitamin D, cholecalciferol, Nepal

\section{Introduction}

Vitamin D deficiency is a global health problem; an estimated 1 billion people across all ethnicities and age groups have deficient or inadequate levels of vitamin D worldwide (1). Vitamin D deficiency is mainly a result of reduced exposure to sunlight, which is essential for ultraviolet-B (UVB)-induced vitamin D production in the skin (2). Previous studies have indicated that vitamin D deficiency may be associated with increased incidence rates of cardiovascular disease, cancer, diabetes and cognitive impairment (3-6). It is considered that vitamin D deficiency is unlikely to occur in regions with adequate sunshine, and as such vitamin D deficiency may be overlooked in the neighboring countries of Nepal, including India and China (7,8). While different boundaries have been proposed to define vitamin D deficiency, Holick (9) defined vitamin D insufficiency as $<30 \mathrm{ng} / \mathrm{ml}$ serum 25-hydroxyvitamin D [25(OH)D], and vitamin D deficiency as a serum $25(\mathrm{OH}) \mathrm{D}$ level $<20 \mathrm{ng} / \mathrm{ml}$. Vitamin D is considered the major sun-induced vitamin, and thus the traditional fashions in Nepal and India, religious or otherwise, may be responsible for vitamin D deficiency (8). In particular, indoor workers are probably unable to achieve normal serum levels of $25(\mathrm{OH})$ D from sun exposure alone. Though vitamin D3 is naturally present in small quantities in foodstuffs including oily fish, eggs and fortified foods, vitamin D supplementation is generally required to achieve the desired threshold concentration of serum $25(\mathrm{OH}) \mathrm{D}$ among deficient individuals (10).

There is no universally accepted threshold at which initiating vitamin D supplementation would achieve the greatest impact. Therapeutic strategies that aid adherence to treatment with the aim of providing long-term vitamin D supplement are of clinical interest. Similar to the trend in India (11), at present, it is common practice by physicians in Nepal to prescribe cholecalciferol at a dose of 60,000 IU/week for two months, then at $60,000 \mathrm{IU} /$ month for six months for occult vitamin D deficiency. However, the short- and longterm effects on serum 25(OH)D levels in Nepalese individuals have not been systematically studied. Therefore, the present study reports on 19 healthy laboratory personnel working at the National Center for Rheumatic Diseases, Kathmandu, Nepal, with severe vitamin D deficiency who received oral 
cholecalciferol at $60,000 \mathrm{IU} /$ week for a duration of 2 months, with the aim of assessing changes in the serum concentration of $25(\mathrm{OH}) \mathrm{D}$ induced by cholecalciferol supplementation.

\section{Materials and methods}

Location. Kathmandu is the capital and largest metropolitan city of Nepal in terms of population, located centrally at an elevation of $\sim 1,400 \mathrm{~m}(4,600$ feet $)$ above sea level in the Kathmandu Valley. At high altitude UVB travels over a shorter distance to the earth's surface and thus the skin is exposed to higher levels, enabling it to produce more vitamin D3; according to Holick et al (12), there is direct correlation of increased previtamin D3 production with increased altitude. Notably, they observed in the Indian city, Agra (169 m altitude), that there was a 5 -fold decrease in previtamin D3 production compared with that at Mount Everest base camp (5,300 m altitude) (12).

Subjects. Between January 2016 and March 2016, a prospective open-label 2-month study was performed on 19 healthy laboratory volunteers (mean age $23.47 \pm 3.18$ years) working at the National Center for Rheumatic Diseases. Serum 25(OH)D level was measured at baseline and after a 2-month regimen with oral cholecalciferol supplement at a dose of $60,000 \mathrm{IU}$ $(1,500 \mu \mathrm{g}) /$ week (Cholirol-60K; Vega Pharmaceuticals Pvt., Ltd., Nepal) in tablet form. The majority of the volunteers $(n=19)$ had insufficient sunlight exposure as they generally worked in the laboratory from 8 a.m. to 6 p.m.

Subjects included in the study were aged 18 years and older, working in the laboratory and available for follow-up after 2 months. Subjects excluded from the study were part time laboratory workers, not available for follow-up and/or taking vitamin $\mathrm{D} \geq 400 \mathrm{IU} /$ day prior to the study. All subjects were counseled to confirm the weekly intake of cholecalciferol and the 2-month follow-up after completion of treatment. Volunteers were advised to retain the same sun exposure pattern during the study period. Drug compliance was also assessed by counting empty sachets. As the study was a pilot, the trial was not registered. The study was conducted according to the guidelines provided in the Declaration of Helsinki (13). Additionally, the study was approved by the Ethics Committee of the National Center for Rheumatic Diseases, and informed written consent was obtained from all patients prior to their enrollment in the study.

Data collection. Vitamin D estimation was performed in the Diagno Labs Pvt., Ltd., Gurgaon, India using an ELISA kit provided by Roche Diagnostics GmbH (06506780160; Mannheim, Germany). Serum 25(OH)D levels were measured by electrochemiluminescence using a fully automated system (Cobas e411; Roche Diagnostics GmbH, Mannheim, Germany). Vitamin D deficiency, insufficiency and sufficiency was defined based on serum $25(\mathrm{OH}) \mathrm{D}$ concentrations of $<20$, 20-30 and 30-100 $\mathrm{ng} / \mathrm{ml}$, respectively (9).

Data analysis. Statistical analysis was performed using SPSS 20.0 software (IBM Corp., Armonk, NY, USA). Data are presented as means \pm standard deviation. A dependent samples t-test was used to compare the means of serum
Table I. General characteristics of study population.

\begin{tabular}{lc}
\hline Variable & Subjects, $\mathrm{n}=19$ \\
\hline Mean age \pm SD, years (range) & $23.47 \pm 3.18(19-31)$ \\
Female, $\mathrm{n}(\%)$ & $15(79)$ \\
Male, $\mathrm{n}(\%)$ & $4(21)$ \\
Mean 25(OH)D level $\pm \mathrm{SD}, \mathrm{ng} / \mathrm{ml}$ & \\
Females & $10.15 \pm 8.45$ \\
Males & $17.80 \pm 13.42$ \\
Vitamin D status, $\mathrm{n}(\%)$ & \\
Deficiency & $17(89.4)$ \\
Insufficiency & $1(5.3)$ \\
Sufficiency & $1(5.3)$ \\
\hline
\end{tabular}

25(OH)D, 25-hydroxyvitamin D; SD, standard deviation.

25(OH)D levels at baseline and after the 2-month regimen with oral cholecalciferol supplement. The statistical testing was two-tailed, and $\mathrm{P}<0.05$ was considered to indicate statistical significance.

\section{Results}

Characteristics of study participants. As presented in Table I, relevant data were available for all 19 subjects included in the study. Participants ranged in age from 19 to 30 years (mean age $23.47 \pm 3.18$ years), and there was a greater proportion of females $(n=15,79.0 \%)$ than males $(n=4,21.0 \%)$. At baseline, 17 subjects (89.4\%) exhibited vitamin D deficiency, $1(5.3 \%)$ exhibited insufficiency and 1 (5.3\%) exhibited sufficiency. The mean $25(\mathrm{OH}) \mathrm{D}$ level of females was $10.15 \pm 8.45 \mathrm{ng} / \mathrm{ml}$ while the mean $25(\mathrm{OH}) \mathrm{D}$ level of males was $17.80 \pm 13.42 \mathrm{ng} / \mathrm{ml}$.

Effect of oral cholecalciferol on serum 25(OH)D concentration. At baseline, the mean 25(OH)D level was $10.31 \pm 7.78 \mathrm{ng} / \mathrm{ml}$, with a minimum of $4 \mathrm{ng} / \mathrm{ml}$ and maximum of $37.6 \mathrm{ng} / \mathrm{ml}$. Following completion of the course of oral cholecalciferol, the serum concentration of $25(\mathrm{OH}) \mathrm{D}$ in all volunteers was in the sufficient range $(30-100 \mathrm{ng} / \mathrm{ml})$. The mean serum level of $25(\mathrm{OH}) \mathrm{D}$ following the supplement course was $59.78 \pm 14.74 \mathrm{ng} / \mathrm{ml}$, with a minimum of $42 \mathrm{ng} / \mathrm{ml}$ and maximum of $94.50 \mathrm{ng} / \mathrm{ml}$ (Fig. 1 and Table I). Notably, following the weekly supplement of cholecalciferol for two months, the increase in the mean serum level of $25(\mathrm{OH}) \mathrm{D}$ compared with baseline was significant to $\mathrm{P}<0.001$ (Table II).

\section{Discussion}

Few studies have been conducted on oral vitamin D3 supplementation in Nepal. However, low levels of vitamin D have been associated with reduced health, particularly by contributing to increased risk of fractures, functional limitations and chronic diseases (3-5). To the best of our knowledge, the present study was the first prospective study in Nepal to evaluate the effect of high dose oral vitamin D3 
Table II. Mean 25(OH)D levels of laboratory personnel at baseline and following cholecalciferol supplement therapy.

\begin{tabular}{lrr}
\hline Serum 25(OH)D level, ng/ml & Mean \pm SD & P-value \\
\hline Baseline & $10.31 \pm 7.78$ & \\
After supplementation & $59.78 \pm 14.74$ & $<0.001$ \\
\hline
\end{tabular}

25(OH)D, 25-hydroxyvitamin D; SD, standard deviation.

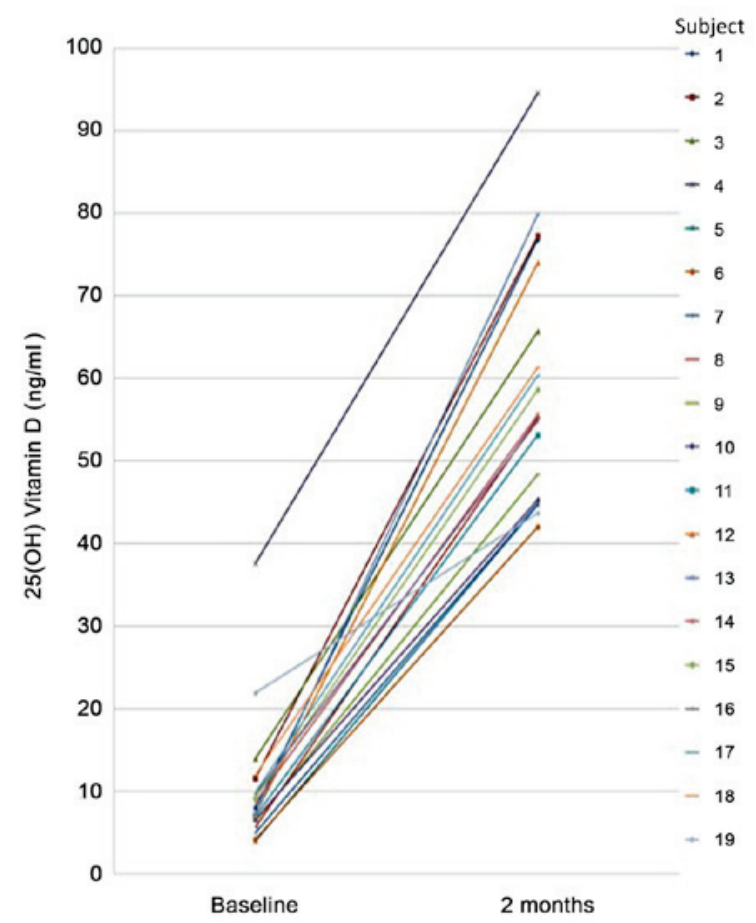

Figure 1. Serum 25-hydroxyvitamin D levels of each participant $(n=19)$ at baseline and following oral cholecalciferol supplementation (60,000 IU/week) for two months.

supplementation (60,000 IU cholecalciferol) on mean serum 25(OH)D concentration among laboratory personnel.

Consistent with previous studies (14-16), the results of the present study indicated that females had lower 25(OH)D levels than males. Traditional and religious clothing habits and lifestyle are considered to be responsible for vitamin D deficiency, particularly in women $(17,18)$. In Nepal, the majority of individuals, particularly females, wear clothes that shield the majority of the skin from sunlight, due to religious beliefs and/or cosmetic concerns, which thus reduces the synthesis of vitamin D.

The major source of vitamin D in humans is sunlight. In the present study, at baseline, the majority of volunteers exhibited deficient 25(OH)D levels. Exposure to sunlight for $\sim 20$ min per day is considered to maintain sufficient levels of vitamin D $(15,16)$. However, all participants in the present study worked in a laboratory during typical sunlight hours ( $\sim 8$ a.m. to 6 p.m.), and thus their sunlight exposure was minimal, which was the probable cause for their vitamin D deficiency, and is in accordance with previous studies $(19,20)$. Roomi et al (18) concluded that indoor occupations were associated with hypovitaminosis $\mathrm{D}$, and a later study on coal mine workers identified vitamin D deficiency and insufficiency among the participants (21). Furthermore, a study in Korea (22) demonstrated that occupational factors including shift work (shifts from $2 \mathrm{pm}$ to midnight, $9 \mathrm{pm}$ to $8 \mathrm{am}$ the following day and 24-hour shifts) and office work were associated with an increased risk of vitamin D deficiency. Similarly, a British cohort study (23) indicated that individuals working at night and for longer hours may be vulnerable to deficits in vitamin D.

As further factors to consider, Wacker et al (24) observed that vitamin D deficiency was associated with weather, time of day, altitude, air pollution and blockage of sunlight by high-rise buildings. Kathmandu is at high altitude, which may be beneficial for the skin regarding its production level of vitamin D3; however, being among the most polluted cities globally, the blockage of sunlight by air pollution may be a reason for deficits in vitamin D (18).

Few studies have indicated the effect of high dose vitamin D on serum 25(OH)D. However, in the present study, following the 2-month regimen of weekly oral cholecalciferol, the mean serum level of $25(\mathrm{OH}) \mathrm{D}$ was significantly increased. This is similar to the findings of Gowda et al (25) and Garrett-Mayer et al (26). Notably, following the oral supplementation regimen, the present study observed an almost 5 -fold increase in serum 25(OH)D level compared with that at baseline. This trend of a rise in serum $25(\mathrm{OH}) \mathrm{D}$ following 2 months of supplementation with cholecalciferol is similar to observations in Indian (11) and Caucasian (27) subjects. Additionally, findings of the present study demonstrated that supplementation with high dose vitamin D3 (60,000 IU/week cholecalciferol) restored serum levels to sufficient levels $(>30 \mathrm{ng} / \mathrm{ml})$ among laboratory personnel, even for those with lower baseline levels.

Although the US Endocrine Society Clinical Practice Guidelines (28) recommends 1,500-2,000 IU/day vitamin D for adults aged 19 years and over, there is currently no recommendation for vitamin D supplementation in Nepal. Thus, health policy-makers should formulate a uniform guideline for the supplementation of vitamin D in Nepal. Furthermore, health professionals working indoors and office workers should be educated on the benefits of vitamin D supplementation.

There were a number of limitations to the present study. Firstly, the majority of study subjects were women, and thus the results may not be generalizable to general populations. Secondly, the sample size was relatively small and there was a lack of consideration of exposure to sunlight, sunscreen application, clothing coverage, dietary information and other vitamin D supplementation, which may have influenced the change in serum $25(\mathrm{OH}) \mathrm{D}$ during the course of the study. Finally, the study was conducted during winter (January to March), and a previous study has demonstrated that there is seasonal variation in sunlight exposure (29). Therefore, the data was not adjusted for seasonal factors, which may have influenced serum 25(OH)D levels. Despite these limitations, the study had several strengths. The effect of high dose, oral vitamin D3 supplementation on mean serum 25(OH)D concentration was investigated among laboratory personnel, which have rarely been studied despite having clinical importance. Thus, the present results may be useful in guiding early 
interventions that prevent vitamin D deficiency, and for the formulation of guidelines to implement vitamin D supplementation among indoor and office workers in Nepal.

In conclusion, to the best of our knowledge, the present study was the first to investigate vitamin D levels in laboratory personnel at baseline and following an oral supplementation regimen with cholecalciferol in Nepal. Vitamin D deficiency is an important but modifiable public health risk in Nepal, though often remains undiagnosed or insufficiently treated. Adequate sun exposure and vitamin D supplementation are key to achieving the vitamin $\mathrm{D}$ requirement of the body. The present findings highlight that vitamin D deficiency is common among laboratory workers. Further prospective studies with larger sample sizes are now required in this direction to examine the correlation between vitamin D deficiency and working conditions.

\section{Acknowledgements}

The tests and medicines in the present study were funded by the Nepal Rheumatic Disease Relief Foundation.

\section{References}

1. Holick MF and Chen TC: Vitamin D deficiency: A worldwide problem with health consequences. Am J Clin Nutr 87: 1080-1086, 2008.

2. Nair R and Maseeh A: Vitamin D: The 'sunshine' vitamin. J Pharmacol Pharmacother: 3: 118-126, 2012.

3. Mozos I and Marginean O: Links between vitamin D deficiency and cardiovascular diseases. BioMed Res Int 2015: 109275, 2015.

4. Ames BN and Wakimoto P: Are vitamin and mineral deficiencies a major cancer risk? Nat Rev Cancer 2: 694-704, 2002.

5. González-Molero I, Rojo-Martínez G, Morcillo S Gutiérrez-Repiso C, Rubio-Martín E, Almaraz MC, Olveira G and Soriguer F: Vitamin D and incidence of diabetes: A prospective cohort study. Clin Nutr 31: 571-573, 2012.

6. Balion C, Griffith LE, Strifler L, Henderson M, Patterson C, Heckman G, Llewellyn DJ and Raina P: Vitamin D, cognition, and dementia: A systematic review and meta-analysis. Neurology 79: 1397-1405, 2012.

7. Babu US and Calvo MS: Modern India and the vitamin D dilemma: Evidence for the need of a national food fortification program. Mol Nutr Food Res 54: 1134-1147, 2010.

8. Yu S, Fang H, Han J, Cheng X, Xia L, Li S, Liu M, Tao Z, Wang L, Hou L, et al: The high prevalence of hypovitaminosis D in China: A multicenter vitamin D status survey. Medicine (Baltimore) 94: e585, 2015.

9. Holick MF: Vitamin D deficiency. N Engl J Med 357: 266-281, 2007.

10. Boyages S and Bilinski K: Seasonal reduction in vitamin D level persists into spring in NSW Australia: Implications for monitoring and replacement therapy. Clin Endocrinol (Oxf) 77: $515-523,2012$.

11. Goswami R, Gupta N, Ray D, Singh N, Tomar N: Pattern of 25 -hydroxy vitamin $\mathrm{D}$ response at short (2 month) and long (1 year) interval after 8 weeks of oral supplementation with cholecalciferol in Asian Indians with chronic hypovitaminosis D. Br J Nutr 100: 526-529 2008.
12. Holick MF, Chen TC, Lu Z and Sauter E: Vitamin D and skin physiology: A D-lightful story. J Bone Miner Res 22: 28-33, 2007.

13. World Medical Association. Declaration of Helsinki-Ethical Principles of Medical Research Involving Human Subjects. Adopted by the 18th WMA General Assembly, Helsinki, Finland, June 1964 and amended by the 55th WMA Assembly, Tokyo, Japan, October 2004.

14. Hammami MM and Yusuf A: Differential effects of vitamin D2 and D3 supplements on 25-hydroxyvitamin D level are dose, sex, and time dependent: A randomized controlled trial. BMC Endocr Disord 17: 12, 2017.

15. Holick MF: Vitamin D: Importance in the prevention of cancers, type 1 diabetes, heart disease, and osteoporosis. Am J Clin Nutr 79: 362-371, 2004.

16. Zittermann A: Vitamin D and disease prevention with special reference to cardiovascular disease. Prog Biophys Mol Biol 92: 39-48, 2006.

17. Buyukuslu N, Esin K, Hizli H, Sunal N, Yigit P and Garipagaoglu M: Clothing preference affects vitamin D status of young women. Nutr Res 34: 688-693, 2014.

18. Roomi MA, Farooq A, Ullah E and Lone KP: Hypovitaminosis D and its association with lifestyle factors. Pak J Med Sci 31: 1236-1240, 2015.

19. Erden G, Ozdemir S, Ozturk G, Erden A, Kara D, Isik S, Ergil J, Vural $C$ and Arzuhal AE: Vitamin D levels of anesthesia personnel, office workers and outdoor workers in Ankara, Turkey. Clin Lab 62: 931-937, 2016.

20. Cinar N, Harmanci A, Yildiz BO and Bayraktar M: Vitamin D status and seasonal changes in plasma concentrations of 25-hydroxyvitamin D in office workers in Ankara, Turkey. Eur J Intern Med 25: 197-201, 2014.

21. Peng M, Chen S, Jiang X, Zhang W, Wang Y, Wu S; Cardiovascular Survey Group OB: Dissociation between low vitamin D level and hypertension in coal mine workers: Evidence from the Kailuan Study. Intern Med 55: 1255-1260, 2016.

22. Jeong H, Hong S, Heo Y, Chun H, Kim D, Park J and Kang MY: Vitamin D status and associated occupational factors in Korean wage workers: Data from the 5th Korea national health and nutrition examination survey (KNHANES 2010-2012). Ann Occup Environ Med 26: 28, 2014.

23. Ward M, Berry DJ, Power C and Hyppönen E: Working patterns and vitamin D status in mid-life: A cross-sectional study of the 1958 British birth cohort. Occup Environ Med 68: 902-907, 2011.

24. Wacker M and Holick MF: Sunlight and Vitamin D: A global perspective for health. Dermatoendocrinol 5: 51-108, 2013.

25. Gowda U, Ruwanpathirana T, Fong DPS, Kaur A and Renzaho AMN: Efficacy of high dose vitamin D supplementation in improving serum $25(\mathrm{OH}) \mathrm{D}$ among migrant and non migrant population: A retrospective study. BMC Health Serv Res 16: 579, 2016.

26. Garrett-Mayer E, Wagner CL, Hollis BW, Kindy MS and Gattoni-Celli S: Vitamin D3 supplementation (4000 IU/d for 1 year) eliminates differences in circulating 25 -hydroxyvitamin D between African American and white men. Am J Clin Nutr 96: 332-336, 2012.

27. Malabanan A, Veronikis IE and Holick MF: Redefining vitamin D insufficiency. Lancet 351: 805-806, 1998.

28. Holick MF, Binkley NC, Bischoff-Ferrari HA, Gordon CM, Hanley DA, Heaney RP, Murad MH, Weaver CM; Endocrine Society: Evaluation, treatment, and prevention of vitamin D deficiency: an Endocrine Society clinical practice guideline. J Clin Endocrinol Metab 96: 1911- 1930, 2011.

29. Hollis BW and Wagner CL: Normal serum vitamin D levels. N Engl J Med 352: 515-516, author reply 515-516, 2005. 